\title{
Congenital disorders of glycosylation. Part II. Defects of protein O-glycosylation
}

\author{
Bogdan Cylwik ${ }^{\bowtie}$, Karina Lipartowska, Lech Chrostek and Ewa Gruszewska \\ Department of Biochemical Diagnostics, Medical University of Bialystok, Białystok, Poland
}

\begin{abstract}
Glycosylation is a form of post-translational modification of proteins and occurs in every living cell. The carbohydrate chains attached to the proteins serve various functions. There are two main types of protein glycosylation: $\mathrm{N}$-glycosylation and $\mathrm{O}-$ glycosylation. In this paper, we describe the 0 -glycosylation process and currently known congenital disorders of glycosylation associated with defects of protein O-glycosylation. This process takes place in the cis Golgi apparatus after N-glycosylation and folding of the proteins. The O-glycosylation is essential in the biosynthesis of mucins, the formation of proteoglycan core proteins and blood group proteins. Most common forms of $\mathrm{O}$-glycans are the mucintype glycans. There are more than 20 known disorders related to O-glycosylation disturbances. We review 8 of the following diseases linked to defects in the synthesis of O-xylosylglycans, O-N acetylgalactosaminylglycans, O-xylosyl/N-acetylglycans, O-mannosylglycans, and Ofucosylglycans: multiple exostoses, progeroid variant of Ehlers-Danlos syndrome, progeria, familial tumoral calcinosis, Schneckenbecken dysplasia, Walker-Warburg syndrome, spondylocostal dysostosis type 3, and Peter's plus syndrome. Causes of these diseases include gene mutations and deficiency of proteins (enzymes). Their diagnosis includes syndromic presentation, organ-specific expression and laboratory findings.
\end{abstract}

Key words: O-glycosylation, genetic defects, diagnostics

Received: 16 May, 2013; revised: 30 August, 2013; accepted: 11 September, 2013; available on-line: 19 September, 2013

\section{INTRODUCTION}

There are two main types of protein glycosylation: $\mathrm{N}$ and O-glycosylation. The first part of this paper presents an overview of $17 \mathrm{CDG}$ limited to the group of protein $\mathrm{N}$-glycosylation disorders with a novel nomenclature, classification, location and reasons for defects, clinical phenotype, and diagnostic approach. The second part of this paper concerns the O-glycosylation. Biosynthesis of O-glycans (as well as $\mathrm{N}$-glycans) can be divided into 3 stages: biosynthesis and activation of monosaccharides in the cytoplasm, transport of nucleotide sugar residues into the endoplasmic reticulum (ER) or the Golgi apparatus and attachment of sugar residues to a protein or to a glycan by specific transferases. O-glycosylation has no processing and thus only consists of assembly that mainly occurs in the Golgi apparatus, contrary to N-glycosylation (Spiro, 2002).

O-glycans (O-linked saccharides) in O-glycoproteins are covalently linked to the hydroxyl group of serine or threonine (or hydroxylysine and hydroxyproline) of the protein. In contrast to $\mathrm{N}$-glycans, O-glycans are built on different protein glycan linkage and have extremely diverse structures (Spiro, 2002). In humans, seven different types of O-glycans are known that are classified on the basis of the first sugar residue attached to amino acid residues (Table 1) (Wopereis et al., 2006a). The most common form of O-glycans are the mucin-type O-glycans. In this type, O-glycans are linked via N-acetylgalactosamine (GalNAc), to a hydroxyl group of serine or threonine residues of the protein core and can be further extended with sugar residues including galactose, $\mathrm{N}$ acetylglucosamine, fucose or sialic acid into a variety of different structural core classes (Spiro, 2002). There are 7 mucin-type core structures (numbers 1-6 and 8) distinguished according to the second sugar residue and its sugar residue linkage (Brockhausen et al., 2009). Mucin O-glycans can be further branched and modificated (by $\mathrm{O}$-acetylation of sialic acids, O-sulfation of galactose and $\mathrm{N}$-acetylglucosamine). Therefore, they constitute a very heterogeneous group of compounds with several hundreds of different mucin-type O-glycan structures. Mucins are found in mucous secretions and as membrane glycoproteins of the cell surface ((Brockhausen et al., 2009). Another common type of O-glycans are glycosaminoglycans (GAGs) that are a long, unbranched carbohydrate part of proteoglycans (Esko et al., 2009). GAGs are attached to the serine of a protein via the linker tetrasaccharide (O-linked xylose-galactose-galactose-glucuronic acid), except for keratan sulfate, which is linked to proteins either through $\mathrm{N}$ - or core $1 \mathrm{O}$-glycans. Most proteoglycans also contain $\mathrm{O}$ - and $\mathrm{N}$-glycans. There are 3 types of GAGs differentiated on the basis of the composition of the disaccharide repeat: dermatan sulfate/ chondroitin sulfate with GlcA and GalNAc, heparin sulfate/heparin with GlcA and GlcNAc and keratin sulfate with Gal and GlcNAc. Additionally, Glc in dermatan sulfate and heparin sulfate/heparin can be epimerized to iduronate. Many forms of proteoglycans are present in virtually all extracellular matrices of connective tissues. The diverse biological function of proteoglycans depend on the interaction of the glycosaminoglycan chains with different protein ligands (Esko et al., 2009). The less common types of glycoprotein linkages are nonmu-

e-mail: cylwikb@umb.edu.pl

Abbreviations: CDG, congenital disorders of glycosylation; CS, chondroitin sulfate; DS, dermatan sulfate; EGF, epidermal growth factor; EMP, extra cellular matrix; ER, endoplasmic reticulum; FTC, familial tumoral calcinosis; GAGs, glycosaminoglycans; Gal NAc, Nacetylgalactosamine; GlcA, glucuronic acid; $\mathrm{HME}$, hereditary multiple exostoses; HS, heparan sulfate; IEF, isoelectric focusing; MEB, muscle-eye-brain; TIEF, transferrin isoelectrofocusing; TSRs, thrombospondin type- 1 repeats; WWS, Walker-Warburg syndrome; aDG, a-dystroglycan. 
cin O-glycans, including $\alpha$-linked O-fucose, $\beta$-linked Oxylose, $\alpha$-linked O-mannose, $\beta$-linked O-GlcNAc, $\alpha$ - or $\beta$-linked $O$-galactose, and $\alpha$ - or $\beta$-linked $O$-glucose glycans (Freeze \& Haltiwanger, 2009).

O-glycosylation is a very complex process involving a number of enzymes which are encoded by multiple genes. Mutations in these genes are the main cause of enzyme deficiency and lead to defects in the biosynthesis of different types of O-glycans. These defects are responsible for a number of diseases named congenital disorders of O-glycosylation. In contrast to N-glycosylation disorders, clinical manifestation of these disorders is usually limited to one organ or organ system without general symptoms, (Spiro, 2002).

This paper summarizes our knowledge about congenital disorders of glycosylation caused by defects in the biosynthesis of protein-linked O-glycans. These defects concern 8 disorders and are associated with the synthesis of O-xylosylglycans, O-N-acetylgalactosaminylglycans, Oxylosyl/N-acetylglycans, O-mannosylglycans, and O-fucosylglycans. Similarly to the first part of the review, this part aims to enhance the access to scientific information about genetic diseases, especially in cases with unknown origin and facilitate their diagnosis.

\section{CHARACTERIZATION OF CDG RELATED WITH IMPAIRED OF O-GLYCOSYLATION}

\section{EXT1/EXT2-CDG: deficiency of glucuronyltransferase/N- acetylglucosaminyltransferase (EC 2.4.1.224 and EC 2.4.1.225)}

This defect has been identified in the synthesis of O-xylosylglycans of some proteoglycans (Heinritz et al., 2009). Generally, proteoglycans consist of a core protein and one or more covalently attached glycosaminoglycan chains (GAGs). Only two classes of glycosaminoglycan chains, namely the chondroitin sulfate/dermatan sulfate (CS/DS) and heparan sulfate/heparin (HS/heparin), are linked to serine residues in core protein by xylose and form O-xylosylglycans (Esko et al., 2009). Chondroitin sulfate proteoglycans (e.g. aggrecan, decorin, biglycan) and heparan sulfate proteoglycan (perlecan) are secreted into the extracellular matrix (ECM). This matrix is a dominant element in the structure of cartilage, bones, ligaments and tendons (Esko et al., 2009).

The biosynthesis of CS and HS is initiated by the formation of a linkage region tetrasaccharide (Esko et al., 2009). After the addition of xylose to the polypeptide chain of protein, a tetrasaccharide linkage is assembled by the transfer of two galactose residues from UDP-Gal catalyzed by the $\beta$-1,4-galactosyltransferase I ( $\beta 4$ GalT7) and $\beta$-1,3-galactosyltransferase II ( $\beta 4$ GalT6) and by the transfer of glucuronic acid residue from UDP-GlcA by the $\beta$-1,3-glucuronosyltransferase onto the oligosaccharide chain. Subsequently, two types of reactions occur: the addition of the first $\mathrm{N}$-acetylglucosamine residues by an enzyme called EXTL3 ( $\alpha-1,4-G l c N A c$ transferase I) for the initiation of HS and the addition of N-acetylgalactosamine residues by an enzyme $\beta-1,4-G a l N A c$ transferase I for creating of CS. The HS tetrasaccharide is further elongated by enzymes named EXT1 ( $\beta-1,4-G l c A$ transferase) and EXT2 ( $\alpha-1,4-G l c N A c$ transferase $)$ that transfer $\mathrm{N}$-acetylglucosamine and glucuronic acid from the corresponding UDP-sugars onto the growing polymer. Next, a series of chain modification reactions including sulfation and epimerization of glucuronic acid to iduronic acid occur (Esko et al., 2009). This disturbance of O-glycosylation concerns the heparan sulfate/heparin.

EXT1/EXT2-CDG is caused by mutations in two genes, EXT1 (extosin 1) and EXT2 (extosin 2), what leads to the deficiency of glucuronyltransferase and $\mathrm{N}$ acetylglucosaminyltransferase, the enzymes responsible for chain polymerization in HS synthesis (Table 2) (Fig. 1) (Jennes et al., 2008). It is assumed that mutations in genes encoding these enzymes impair the synthesis of a glycosaminoglycan that exert a tumor-suppressor function (Heinritz et al., 2009). Heparan sulfate cannot be processed correctly and is nonfunctional. Mutations in EXT1 and EXT2 are responsible for the hereditary multiple exostoses and account for $60-70 \%$ and $30-40 \%$ of HME type I and HME type II patients, respectively (Heinritz et al., 2009). HME may be considered a congenital disorder of glycosylation according to the new CDG nomenclature suggested in 2009 (Jaeken et al., 2009).

EXT1/EXT2-CDG was first reported in 1961 in the study of families consisting of 6 persons with diaphyseal aclasis (multiple exostoses). The families were Chamorros, Micronesian people who live in the Mariana Islands (Krooth et al., 1961). In 1993, Beighton analyzed the skeletons of adults in the Museum of Pathological Anatomy in Vienna (Beighton et al., 1993). He pictured the skeleton of a man with multiple exostoses who died in 1842 of ruptured aortic aneurysm (probably syphilitic). Hereditary multiple exostoses is a rare medical condition in which people develop multiple benign bone tumors called exostoses. HME is an autosomal dominant inheritance with a prevalence of about 1:50000. This disorder is characterized by growth of multiple osteochondromas (benign cartilage-capped bone tumors that grow outward from the metaphyses of long bones). Osteochondromas can be associated with a reduction in skeletal growth, bony deformity, restricted joint motion, shortened stature, premature osteoarthrosis, and compression of peripheral nerves. Multiple exostoses can cause growth disturbances of arms, hands, and legs. The risk of malig-

Table 1. Different types of O-linked glycans in humans (Brockhause et al., 2009; Esko et al., 2009; Freeze \& Haltiwanger, 2009).

\begin{tabular}{|c|c|c|}
\hline Type of O-linked glycan & Structure and peptide linkage & Glycoprotein \\
\hline Mucin type & (R)-GalNAca1-Ser/Thr & Plasma membrane, secreted \\
\hline GAG & (R)-GlcAß1,3Gal $\beta 1,3$ Gal $\beta 1,4 X y \mid \beta 1-S e r$ & Proteoglycans \\
\hline O-linked GlcNAc & GlcNAcß1-Ser/Thr & Nuclear and cytoplasmic \\
\hline O-linked Gal & Glca1,2Galß1-O-Hyl/Hyp & Collagens \\
\hline O-linked Man & NeuAca2,3Galß1,4GIcNAcß1,2Mana1-Ser/Thr & a-dystroglycan \\
\hline O-linked Glc & Xyla1-3Xyla1,3Glc $\beta 1-S e r$ & Epidermal growth factor (EGF) protein domains \\
\hline O-linked Fuc & $\begin{array}{l}\text { NeuAca } 2,3 / 6 \text { Gal } \beta 1,4 \text { GlcNac } \beta 1,3 F u c a 1-S e r / T h r, \\
\text { Glc } \beta 1,3 F u c a 1-S e r / T h r\end{array}$ & $\begin{array}{l}\text { Epidermal growth factor (EGF) protein domains } \\
\text { Thrombospondin type- } 1 \text { repeats (TSR repeats) }\end{array}$ \\
\hline
\end{tabular}


Table 2. Genetic defects in the O-glycosylation pathway- related CDG disorders (Freeze \& Schachter, 2009; OMIM, 2013).

\begin{tabular}{|c|c|c|c|}
\hline CDG Type & Gene symbol & Protein name & $\begin{array}{l}\text { Phenotype OMIM* } \\
\text { number }\end{array}$ \\
\hline EXT1/EXT2-CDG & EXT1/EXT2 & Glucuronyltransferase/N-acetylglucosaminyltransferase & $\begin{array}{l}133700 \\
133701\end{array}$ \\
\hline B4GALT7-CDG & $B 4 G A L T 7$ & $\beta$-1,4-galactosyltransferase I ( $\beta$ 4GalT7) & 130070 \\
\hline GALNT3-CDG & GALNT3 & $\mathrm{N}$-acetylgalactosaminyltransferase 3 & 211900 \\
\hline SLC35D1-CDG & SLC35D1 & UDP-GIcA/UDP-GalNAc Golgi dual transporter & 610804 \\
\hline POMT1/POMT2-CDG & POMT1/ POMT2 & O-mannosyltransferase 1/O-mannosyltransferase 2 & 236670 \\
\hline POMGNT1-CDG & POMGNT1 & O-mannosyl- $\beta-1,2-\mathrm{N}$-acetylglucosaminyltransferase 1 & 253280 \\
\hline SCDO3-CDG & LFNG & O-fucose-specific $\beta-1,3-\mathrm{N}$-acetylglucosaminyltransferase & 609813 \\
\hline B3GALTL-CDG & B3GALTL & $\begin{array}{l}\beta-1,3 \text {-glucosyltransferase specific for O-fucose-linked gly- } \\
\text { cans on thrombospondin type } 1 \text { repeats }\end{array}$ & 261540 \\
\hline
\end{tabular}

*OMIM, Online Mendelian Inheritance in Man (updated 25 January 2013)

nant degeneration to osteochondrosarcoma is low (about $1 \%$ ). The proportion of individuals with HME who have clinical findings increases from approximately 5\% at birth to $96 \%$ at the age of 12 years (Legeai-Mallet et al., 1997).

There are no laboratory tests that have been reported for the diagnosis of HME. It is mostly based on clinical and/or radiographic findings of multiple exostoses in one or more members of a family. The diagnosis can be further confirmed by mutation analysis of the EXT1 and EXT2 genes (Philippe et al., 1997).

\section{B4GALT7-CDG: deficiency of $\beta$-1,4-galactosyltransferase I (B4GalT7) (EC 2.4.1.133)}

The defect is associated with the synthesis of O-xylosylglycans of proteoglycans such as chondroitin sulfate/ dermatan sulfate and heparan sulfate/heparin (Faiyaz-UlHaque et al., 2004). As described above, the biosynthe-

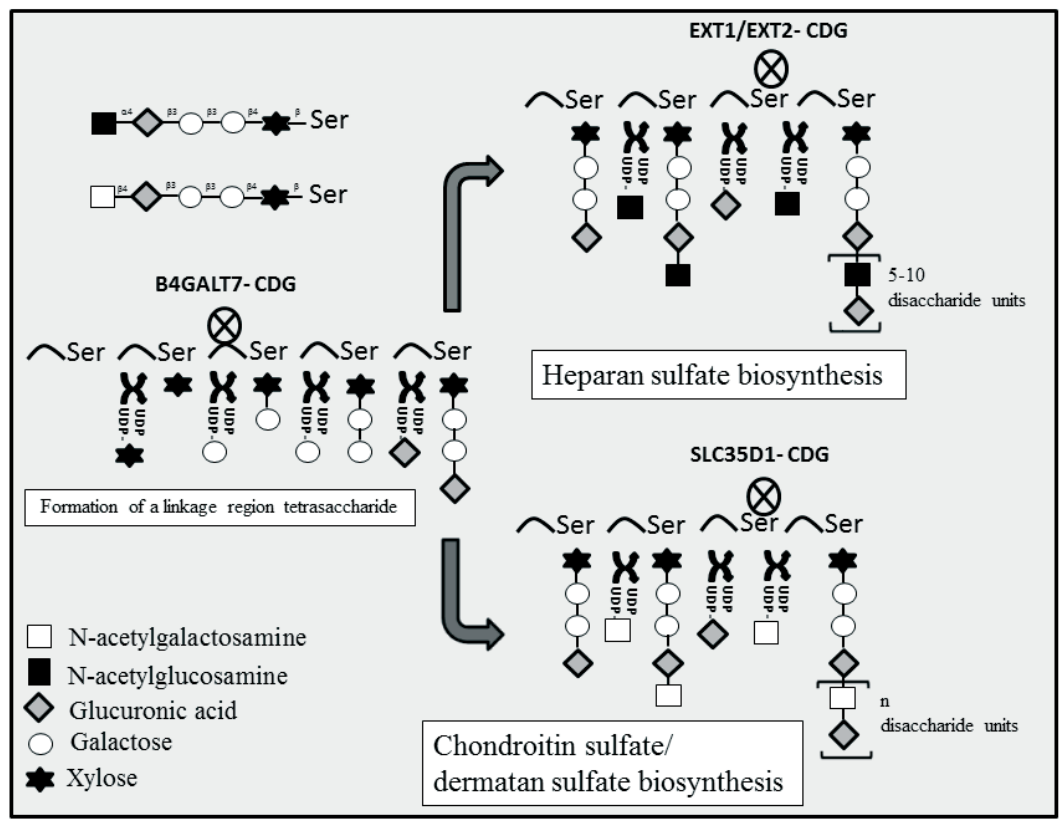

Figure 1. Location of defects in the biosynthesis of proteoglycan glycosaminoglycans. B4GALT7-CDG, $\beta-1,4-G a l$ transferase 7 - congenital disorders of glycosylation; EXT1/EXT2CDG; extosin 1/extosin; Ser, serine; SLC35D1-CDG, soluble carrier family 35, member D1; UDP, uridine diphosphate. sis of these proteoglycans starts with the formation of a tetrasaccharide linkage region (O-linked xylose-galactosegalactose-glucuronic acid) (Esko et al., 2009). Glycosaminoglycans are attached to a serine residue of a protein via this tetrasaccharide linker. At the beginning of this process, after the addition of xylose to the polypeptide chain of a protein, the enzyme $\beta$-1,4-galactosyltransferase I ( $\beta 4$ GalT7) transfers the first galactose from UDP-Gal onto xylose, forming disaccharide (O-linked xylose-galactose). This enzyme is encoded by the B4GALT7 gene that is expressed in many organs (heart, pancreas, liver, placenta, kidney, brain, skeletal muscle, lung).

B4GALT7-CDG results from mutations in the B4GALT7 gene that leads to the deficiency of $\beta 4 \mathrm{GalT} 7$ and of progeroid variant of Ehlers-Danlos syndrome (Faiyaz-Ul-Haque et al., 2004) (Table 2) (Fig. 1). Clinical phenotype of this disorder was first reported in 1987 in a boy aged 4 years 9 months, with features of both Ehlers-Danlos syndrome and progeria. In addition to delayed mental development, there were multiple abnormalities of connective tissue, including short stature, osteopenia of all bones, and hyperelastic skin, hypotonic muscles, and hypermobile joints (Kresse et al., 1987). Up till now, only 6 patients have been recognized (OMIM, 2013).

Laboratory tests for the assessment of thyroid, kidney, and liver functions are normal (Faiyaz-Ul-Haque et al., 2004). The serum creatine kinase and growth hormone levels are within the reference range. The diagnosis can be performed by the determination of $\beta 4$ GalT7 activity in human fibroblast (Quentin et al., 1990). It has been shown that this activity was reduced to a level less than one-twentieth of normal (Okajima et al., 1999). The reduced $\beta 4 \mathrm{GalT} 7$ activity disrupts the disaccharide linker region of glycosaminoglycans (Faiyaz-Ul-Haque et al., 2004). 
Skin fibroblasts converted only about half of the core protein of the small proteodermatan sulfate to a mature glycosaminoglycan chain-bearing proteoglycan (Kresse et al., 1987). The diagnosis can be further confirmed by the B4GALT7 gene mutations (Okajima et al., 1999).

\section{GALNT3-CDG: deficiency of} $\mathrm{N}$-acetylgalactosaminyltransferase 3 (EC 2.4.1.41)

This defect has been found in the synthesis of mucin O-GalNAc glycans (O-N-acetylgalactosaminylglycans) (Chefetz \& Sprecher, 2009). Mucins may have a large number of O-GalNAc glycans (Brockhausen et al., 2009). Mucin-type O-glycosylation is one of the most abundant forms of glycosylation of proteins, and is found on a large variety of cell membranes and secreted glycoproteins. O-glycosylation imparts unique physicochemical features to glycoproteins which have been shown to play important functions in almost all known biological processes including intracellular sorting, cell-cell adhesion, and microbial adhesion events (Jentoft, 1990). More than twenty different $\mathrm{N}$-acetylgalactosaminyltransferases catalyze the initial, enzymatic step of mucin-type O-glycosylation in the Golgi complex, transferring N-acetylgalactosamine from UDP-GalNAc to serine or threonine residues of a protein backbone. These enzymes are encoded by different genes and their expression depend on the cell types and tissues (Ten Hagen et al., 2003; Brockhausen et al., 2009). Although all these enzymes transfer the same monosaccharide (N-acetylgalactosamine), but onto the various protein substrates.

GALNT3-CDG is due to the mutations in the GALNT3 gene and leads to the deficiency of isoform 3 of N-acetylgalactosaminyltransferase (Table 2) (Fig. 2) (Chefetz \& Sprecher, 2009). GALNT3 gene is expressed in organs that contain secretory epithelial glands and many other, such as pancreas, skin, kidney, testis, prostate, ovary, intestine, and colon (Bennett et al., 1996). The deficiency of $\mathrm{N}$-acetylgalactosaminyltransferase causes familial tumoral calcinosis (FTC). Hereditary idiopathic calcinosis was first described more than a century ago by Giard and Duret (Giard, 1898; Duret, 1899). The disease has been mainly reported in patients of Middle Eastern or African ancestry (McClatchie \& Bremner, 1969). FTC

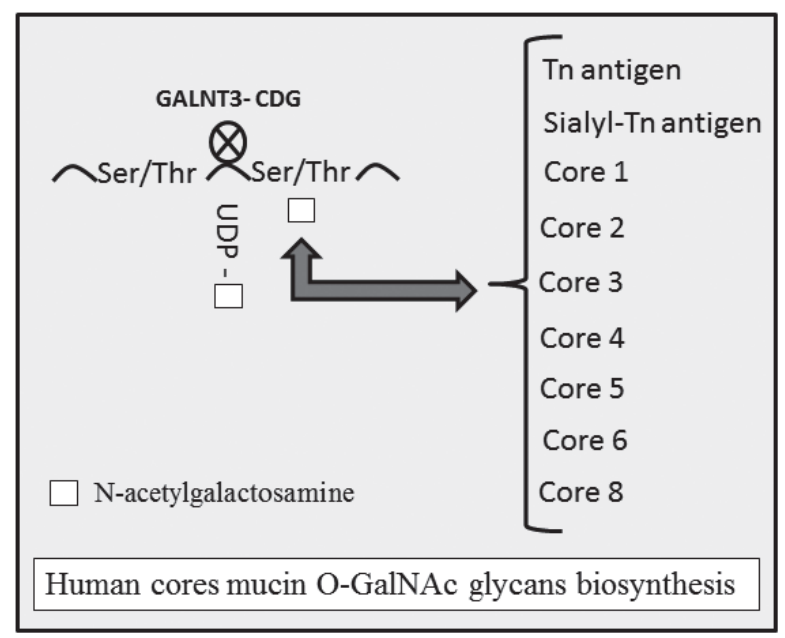

Figure 2. Location of the defect in the mucin O-GaINAc glycans biosynthesis.

GALNT3-CDG, N-acetylgalactosaminyltransferase 3 - congenital disorders of glycosylation; Tn antigen, GalNAc-Ser/Thr; GalNAc, $\mathrm{N}$-acetylgalactosamine; Ser/Thr, serine/threonine; UDP, uridine diphosphate. is a severe autosomal recessive metabolic disorder that manifests with hyperphosphatemia and massive calcium deposits in the skin and subcutaneous tissues. This can be complicated by secondary infections and incapacitating mutilations. The disease manifests with paroxysmal episodes of excruciating pain along the long bones, associated with radiographic evidence of hyperostosis. The calcium deposists are probably due to the fact that the enzyme GalNAc-T3 uses calcium and manganese as cofactors to catalyze the first reaction in mucin-type $\mathrm{O}$ glycosylation.

Laboratory tests show increased serum levels of phosphorus, calcium, active vitamin $\mathrm{D}$, and parathyroid hormone. The hyperphosphatemia is due to the increased re-absorption of phosphate through the renal proximal tubule (Chefetz \& Sprecher, 2009). Radiographs presents osteopenia, patchy sclerosis in the hands, feet, long bones and calvaria, intracranial calcifications, and calcifications of the dura and carotid arteries (Chefetz \& Sprecher, 2009). The diagnosis of FTC can be carried out based on the immunostaining of skin biopsy samples with a monoclonal antibody against GalNT3 (Topaz et al., 2005). The recognition can be further confirmed by mutations of the GALNT3 gene (Topaz et al., 2004).

\section{SLC35D1-CDG: deficiency of the UDP-GICA/UDP-GaINAC Golgi dual transporter}

The defect has been recognized in the synthesis of Oxylosyl/N-acetylgalactosaminylglycans and concerns glycosaminoglycan chains of proteoglycans, such as chondroitin sulfate/dermatan sulfate (Muraoka, 2001). These proteoglycans consist of a protein core, a tetrasaccharide linker and one or more (about 100) covalently attached unbranched chains containing repeated disaccharide units (polymerization chain) composed of $\mathrm{N}$-acetylgalactosamine and glucuronic acid (about 80 sugar residues) arranged in the sequence GalNAc $\beta 1,4 \mathrm{GlcA} \beta 1,3$. These chains are further modificated (sulfation and epimerization) (Esko et al., 2009). The chains have different lengths depending on the protein type. The UDP-GlcA/ UDP-GalNAc solute dual transporter is a specific nucleotide sugar residue carrier that translocates glucuronic acid and $\mathrm{N}$-acetylgalactosamine from the cytoplasm into Golgi apparatus (Muraoka, 2001). Both monosaccharides are needed for chondroitin sulfate biosynthesis. This transporter is encoded by the SLC35D1 gene.

SLC35D1-CDG is caused by mutations in the SLC35D1 gene and leads to the deficiency of the UDPGlcA/UDP-GalNAc dual transporter and to Schneckenbecken dysplasia (Table 2) (Fig. 1) (Hiraoka et al., 2007). Schneckenbecken dysplasia is a very rare, severe skeletal dysplasia that is characterized by extremely short long bones, ribs, head and stature, and snail-shaped ilia (Hiraoka et al., 2007; Furuichi et al., 2009). These mutations are predicted to produce truncated proteins.

The diagnostics of Schneckenbecken dysplasia includes clinical, radiological, and histological findings (Hiraoka et al., 2007). The recognition should be confirmed by genetic testing (Furuichi et al., 2009).

\section{POMT1/POMT2-CDG: deficiency of O-mannosyltransferase (EC 2.4.1.109)}

This defect has been identified in the synthesis of Omannosylglycans (Hewitt, 2009). The enzyme O-mannosyltransferase (heterodimer protein: POMT1/POMT2) catalyzes the first step in the synthesis of O-mannose glycans in the ER, transferring the mannose from DolP-Man donor onto the serine/threonine of polypeptide 


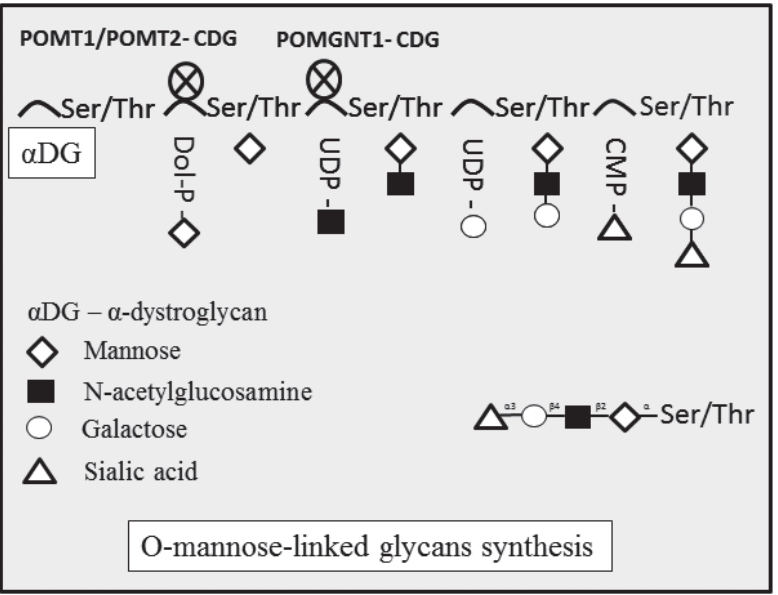

Figure 3. Location of defects in the O-mannose-linked glycans biosynthesis.

CMP, citidine monophosphate; Dol-P, dolichol phosphate; POMGNT1-CDG, O-mannosyl- $\beta-1,2-\mathrm{N}$-acetylglucosaminyltransferase 1- congenital disorders of glycosylation; POMT1/POMT2CDG, O-mannosyltransferase 1/O-mannosyltransferase 2; Ser/Thr serine/threonine; UDP, uridine diphosphate.

chain of protein (Freeze \& Haltiwanger, 2009). Further, in the Golgi apparatus, the $\mathrm{N}$-acetylglucosaminyltransferase (POMGNT1) adds $\beta 1,2$ linked N-acetylglucosamine to O-mannose-containing glycoproteins. Subsequently, the O-mannose glycan is extended with galactose and sialic acid residues by unspecified transferases (Freeze \& Haltiwanger, 2009). Of special interest is the protein $\alpha$-dystroglycan $(\alpha \mathrm{DG})$, in which two thirds of the O-linked mannose chains have the following structure: Sia $\alpha 2,3 \mathrm{Gal} \beta 1,4 \mathrm{GlcNAc} \beta 1,2 \mathrm{ManSer} / \mathrm{Thr}$ (Freeze \& Haltiwanger, 2009). This protein is the main component of the dystrophin-glycoprotein complex on the sarcolemma of skeletal muscle cells. The $\alpha$-dystroglycan binds to $\beta$-dystroglycan in the cell membrane and to laminin in the extracellular matrix. The degree and type of $\alpha \mathrm{DG}$ glycosylation vary in different tissues. O-mannose-based glycans also account for one third of all O-linked glycans in the brain (Freeze \& Haltiwanger, 2009).

POMT1/POMT2-CDG is mainly caused by mutations in two genes, POMT1 (in 20\% of Walker-Warburg syndrome patients) and POMT2 (accounts for a few percent of Walker-Warburg syndrome patients) and leads to the deficiency of O-mannosyltransferase with defective $\alpha$-dystroglycan glycosylation (Table 2) (Fig. 3) (Kim et al., 2004; Hewitt, 2009). Co-expression of these genes is necessary for the proper enzymatic activity (Manya $\mathrm{H}$ et al., 2004). POMT1 is mainly expressed in human testis, heart, and pancreas, and POMT2 only in testis (van Reeuwijk, 2005). The deficiency of O-mannosyltransferase causes the Walker-Warburg syndrome (WWS), the most severe form of the congenital muscular dystrophies with brain and eye anomalies. The first case of WalkerWarburg syndrome was reported in 1942 by Walker and labeled lissencephaly (Greek, "smooth brain") (Walker, 1942). This is a genetically heterogeneous autosomal recessive disorder with characteristic brain and eye malformations, profound mental retardation, and congenital muscular dystrophy. The phenotype commonly includes cobblestone lissencephaly, cerebellar malformations, and retinal malformations. More variable features include macrocephaly or microcephaly, hypoplasia of midline brain structures, ventricular dilatation, microphthalmia, cleft lip/palate, and congenital contractures. Patients with Walker-Warburg syndrome often die within the first year of life (Hewitt, 2009).

Patients affected by WWS show increased serum creatine kinase activity and staining of $\alpha$-dystroglycan by VIA4-1 and/or IIH6 monoclonal antibodies was abnormal (Cormand et al., 2001; Beltran-Valero de Bernabe D et al., 2002; Sabatelli et al., 2003). The diagnosis can be performed by the determination of O-mannosyltransferase activity in kidney cells (Manya et al., 2004). For further confirmation of the diagnosis, genetic studies are required (Beltran-Valero de Bernabe D et al., 2002).

\section{POMGNT1-CDG: deficiency of O-mannosyl- $\beta 1-2$ $\mathrm{N}$-acetylglucosaminyltransferase 1 (EC 2.4.1.101)}

The defect affects the synthesis of O-mannosylglycans (Hewitt, 2009). The enzyme O-mannosyl- $\beta 1,2-\mathrm{N}$ acetylglucosaminyltransferase 1 catalyzes the second step in the synthesis of O-mannose glycans in the Golgi apparatus, transferring $\mathrm{N}$-acetylglucosamine residue from UDP-GlcNAc onto mannose residue-containing glycoprotein and creating disaccharide (mannose-N-acetylglucosamine) (Freeze \& Haltiwanger, 2009). This enzyme is encoded by POMGNT1 (Diesen et al., 2004).

POMGNT1-CDG is caused by mutations in the POMGNT1 gene that lead to the deficiency of O-mannosyl- $\beta 1,2-\mathrm{N}$-acetylglucosaminyltransferase 1 (Table 2) (Fig. 3) (Diesen et al., 2004; Hewitt, 2009). This deficiency causes muscle-eye-brain disease (MEB), which is characterized by symptoms similar to those in the Walker-Warburg syndrome, but are less severe. The disorder was first described in 1977 in Finland (Santavuori et al., 1977). The most severely affected patients die during the first years of life (Hewitt, 2009).

Patients with MEB have increased serum creatine kinase activity and abnormal staining of $\alpha$-dystroglycan by VIA4-1 and/or IIH6 monoclonal antibodies (Cormand et al., 2001; Kano et al., 2002). Diagnosis can be done by measuring of the O-mannosyl- $\beta 1,2-\mathrm{N}$-acetylglucosaminyltransferase activity in muscle biopsies (Zhang et al., 2003). For further confirmation of the diagnosis of MEB, genetic analysis is needed (Diesen et al., 2004).

\section{SCDO3-CDG: deficiency of O-fucose-specific $\beta-1,3-\mathrm{N}$ - acetylglucosaminyltransferase (EC 2.4.1.222)}

The defect concerns the synthesis of O-fucosylglycans (Sparrow et al., 2006). The disturbance appears in the Ofucose glycosylation pathway in the epidermal growth factor (EGF)-like repeats. EGF-like repeats are small protein motifs comprising about 40 amino acids residues occuring in a large number of cell-surface and secreted proteins (Freeze \& Haltiwanger, 2009). These domains are part of the proteins involved in blood clot formation and dissolution, the Notch family of receptors and ligands (Delta and Serrate/Jagged), and the Cripton/FRL/Criptic (CFC) family of protein. The O-glycans play a key role, because they modulate signal transduction pathway by changing the interaction between EGF-like repeats and other proteins in a number of human diseases, including some cancers. There is one site for $\mathrm{O}$-fucose glycosylation in the EGF-like repeat. Fucose can be elongated to a tetrasaccharide: Sia $2,3 / 6 \mathrm{Gal} \beta 1,4 \mathrm{GlcNAc} \beta 1,3 \mathrm{Fuc}-\mathrm{O}-$ Ser/Thr. The first step is catalyzed by the O-fucosyltransferase (POFUT1) that transfers fucose from GDPfucose onto the serine/threonine of polypeptide chain of protein. Further, O-fucose can be extended by a specific $\beta-1,3-\mathrm{N}$-acetylglucosaminyltransferase that adds $\mathrm{N}$-acetylglucosamine residues to $\mathrm{O}$-fucose. The formed disaccharide is further elongated by the galactosyl- $\beta 1,4$-transferases 


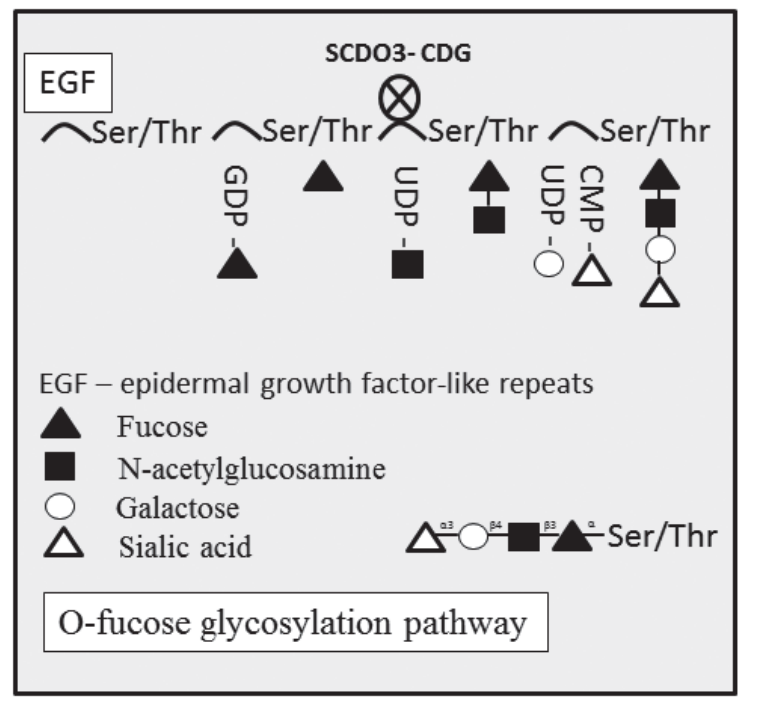

Figure 4. Location of the defect in the O-fucose glycosylation pathway in the epidermal growth factor (EGF)-like repeats. CMP, citidine monophosphate; GDP, guanosine diphosphate; SCDO3-CDG, spondylocostal dysostosis $\mathrm{O} 3$ - congenital disorders of glycosylation; Ser/Thr, serine/threonine; UDP, uridine diphosphate.

that attaches the galactose residue and by the $\alpha 2,3 / 6-$ sialyltransferases which add sialic acid residues (Freeze \& Haltiwanger, 2009).

SCDO3-CDG is caused by the mutation in the third Notch pathway gene, LUNATIC/FRINGE (LFNG), and leads to the deficiency of a specific $\beta-1,3-\mathrm{N}$ acetylglucosaminyltransferase that modifies the Notch family of cell-surface receptors, an important step in the regulation of this signaling pathway (Table 2) (Fig. 4) (Sparrow et al., 2006). This mutation leads to the spondylocostal dysostosis type 3, which is a heterogeneous group of vertebral malsegmentation disorders that arise during embryonic development by the disruption of somitogenesis (Sparrow et al., 2006).

The diagnosis of SCDs can be performed by the determination of $\beta-1,3-\mathrm{N}$-acetylglucosaminyltransferase activity and confirmed by genetic testing (Sparrow et al., 2006).

\section{B3GALTL-CDG: deficiency of $\beta$-1,3-glucosyltransferase specific for 0 -fucose-linked glycans on thrombospondin type 1 repeats (EC 2.4.1.x)}

Thrombospondin type 1 repeats (TSRs) are small proteins motifs composed of 50-60 amino acid residues and occur in many cell-surfaces and secreted proteins in human (Lawler \& Hynes, 1986). The human genome encodes about 100 TSRs-containing proteins that perform a variety of important biological functions (Tucker, 2004). For example, TSRs modules are part of the thrombospondin-1, thrombospondin-2, properdin, F-spondin, and all ADAMTS (disintegrin and metalloproteinase with thrombospondin motif) (Freeze \& Haltiwanger, 2009). TSRs modulate cell-to-cell and cell-to-matrix interactions and have been identified as negative regulators of angiogenesis. They also regulate cell proliferation, migration, and apoptosis in a variety of physiological and pathological settings, including wound healing, inflammation, and neoplasia (Tucker, 2004). In the polypeptide chain of TSRs are the one site designed for O-fucose glycosylation. The $\mathrm{O}$-fucose site can be elongated to form a disaccharide with the structure Glc $\beta 1,3$ Fuc $\alpha$-O-Ser/Thr. The biosyn-

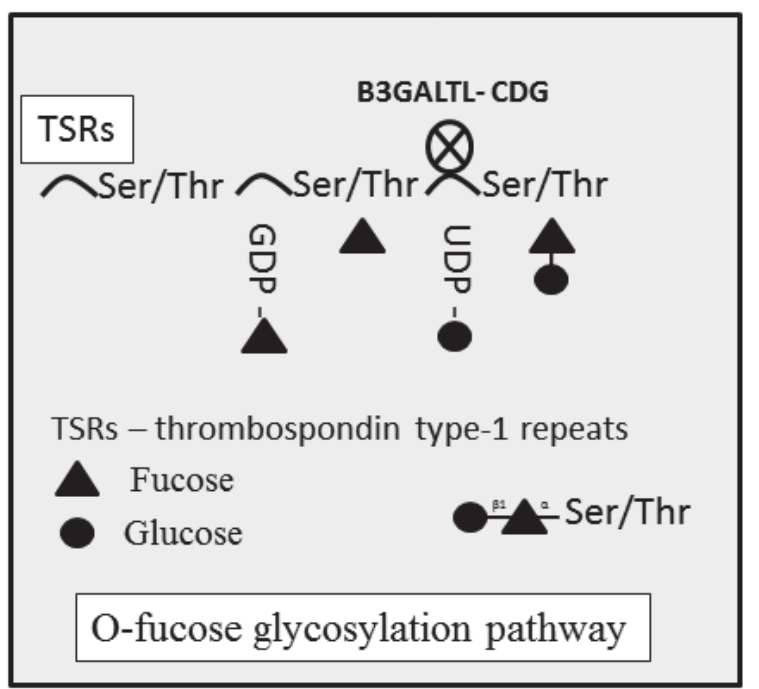

Figure 5. Location of the defect in the O-fucose glycosylation pathway in the thrombospondin type-1 repeats (TSRs). B3GALTL-CDG, $\beta-1,3-$ glucosyltransferase specific for O-fucoselinked glycans on thrombospondin type 1 repeats - congenital disorders of glycosylation; GDP, guanosine diphosphate; Ser/Thr, serine/threonine; UDP, uridine diphosphate.

thesis of this structure is initiated by the O-fucosyltransferase 2 (POFUT2), which attaches the fucosyl residue to serine or threonine of protein. Subsequently, the enzyme $\beta$-1,3-glucosyltransferase adds glucose to $\mathrm{O}$-fucose (Hess et al., 2008). Both enzymes, POFUT2 and $\beta-1,3-$ glucosyltransferase are localized in the ER. For example, abolishing O-fucosylation causes a diminished secretion of ADAMTS-like 1 and ADAMTS 13 (Ricketts et al., 2007).

B3GALTL-CDG is caused by mutations in the B3GALTL gene and leads to the deficiency of $\beta-1,3-$ glucosyltransferase and defects in the synthesis of O-fucosylglycans (Table 2) (Fig. 5) (Hess et al., 2008). It was found that B3GALTL does not in fact code for galactosyltransferase but rather for glucosyltransferase (Hess et al., 2008). These mutations cause a genetic disorder known as the Peter's Plus syndrome (Hess et al., 2008). Peter's Plus syndrome is an autosomal recessive disorder characterized by peculiar eye malformations including corneal opacities and iridocorneal adhesions besides growth retardation and variable abnormalities in other organs.

Serum levels of properdin, determined by ELISA, in patients with Peter's Plus syndrome are slightly reduced (Hess et al., 2008). To confirm the diagnosis, genetic studies are needed (Hess et al., 2008).

\section{LABORATORY DIAGNOSTICS OF CDG}

Diagnosis of congenital disorders of O-glycosylation is mainly based on genetic approaches. Very important is the O-glycan structure analysis and the determination of specific enzymes responsible for defects in O-glycosylation pathway. Ten years ago, the IEF assay of plasma apolipoprotein C-III (apoC-III) was introduced, for the screening of inborn errors in the biosynthesis of mucin-type core 1 O-glycans (Wopereis et al., 2003). ApoC-III carries a single O-glycan terminally modified by up to two sialic acids and is not N-glycosylated (Vaith et al., 1978). Three isoforms of apoC-III can be distinguished using IEF: apoC-III ${ }_{0}$, apoC$\mathrm{III}_{1}$ and apoC- $\mathrm{III}_{2}$. The ratio of these isoforms is normal in the healthy individuals, but it is abnormal (hypoglycosylation profile) when the biosynthesis of core 1 O-glycan is 
disturbed (Wopereis et al., 2003). The apoC-III profile of patients with disturbed core 1 mucin-type O-glycan biosynthesis shows increased amounts of apoC- $\mathrm{II}_{0}$ and/or apoC$\mathrm{III}_{1}$ compared to the IEF profile of apoC-III in healthy subjects. The apoC-III isoform profile in combination with transferrin IEF can be used to identify combined defects in N-glycan and mucin-type core 1 O-glycan biosynthesis (Wopereis et al., 2007). Based on the IEF profile of plasma transferrin and apoC-III, a combined defect in $\mathrm{N}$ and $\mathrm{O}-$ glycosylation was identified in patients with autosomal recessive cutis laxa type II (ARCL II) (Wopereis et al., 2005). These patients had disialo- type II transferrin isoform profile, decreased apoC-III , and increased apoC-III 1 . Hypersialylated core $1 \mathrm{O}$-glycans and normal sialylation of $\mathrm{N}$ glycans were observed in patients with sialuria (Wopereis et al., 2006). In turn, unsialylated core 1 O-glycans and normal serum transferrin isoform profile were detected in patients with CDG-IIf (Martinez-Duncker et al., 2005).

For the screening of defects in O-mannosyl glycan biosynthesis $\alpha$-dystroglycan is used, which is a highly $\mathrm{O}$ mannosylated protein that is the only known substrate for this type of glycosylation in mammals (Michele et al., 2002). Immunohistochemical staining of this protein with the monoclonal antibody VIA4-1 allows for the recognition of a carbohydrate epitope on $\alpha$-dystroglycan specifically and polyclonal antibody $\mathrm{p} \alpha \mathrm{DAG}$ against the $\mathrm{C}$-terminal end of this protein in muscle biopsies (Beltran-Valero de Bernabe D et al., 2002). VIA4-1 shows a complete lack of staining in muscle biopsies of patients with Walker-Warburg syndrome, and paDAG presents a marked reduction of $\alpha$-dystroglycan peptide in many fibers (Beltran-Valero de Bernabe D et al., 2002).

There are no screening tests to identify the defects in glycosaminoglycans biosynthesis that are carbohydrate part of proteoglycans. In normal patients, large amounts of GAGs occur in urine. It seems that patients with defects in the glycosaminoglycans biosynthesis pathway may have reduced excretion in the urine. Determination of GAGs in urine is generally used as a screening procedure for mucopolysaccharidoses (MPS). A simple and reliable procedure in urine for MPS is based on the color reaction of glycosaminoglycans with dimethylmethylene blue (de Jong et al., 1992).

To test the O-glycans they must be firstly released from proteins, then enriched, and analyzed (Zauner et al., 2012). The separation can be performed in two ways: enzymatic and chemical. The enzymatic way is limited to endo- $\alpha-\mathrm{N}$ acetylgalactosamidase, an O-glycanase that only enable the removal of core 1 disaccharides (Galß1-3GalNAc) from serine or threonine. Therefore, best methods for universal liberation of O-glycans are chemical procedures, including reductive or non-reductive $\beta$-elimination. Current methods for the analysis of glycans can be divided into two categories: compositional mass profiling and structure-specific chromatographic profiling. The first procedure uses highresolution mass spectrometry (MS) to rapidly separate and identify glycans based on accurate mass. Mass spectrometry is currently the best method for profiling glycans due to its sensitivity and speed of analysis. Glycans may be chromatographically fractionated offline and spotted for MALDI (Matrix Assisted Laser Desorption Ionisation) or separated online by methods such as the reversed phase (RP) liquid chromatography (LC), immediately prior to the introduction into the mass spectrometer via electrospray ionization (ESI). There are about 50 techniques/methods linked with mass spectrometry for O-glycan structure analysis, e.g, tandem MS/MS, MALDI-MS, MALDI-TOFMS (Matrix Assisted Laser Desorption Ionisation-Time of flight-Mass spectrometry) (Zauner et al., 2012).

\section{SUMMARY}

Progress of knowledge on the congenital disorders of glycosylation and development of research methods cause their number to rapidly grow. This review provides a current summary on the CDG which affect the O-glycan biosynthesis. We present 8 different genetic disorders of O-glycosylation and their biochemical, molecular, genetic, clinical, and laboratory aspects. The defects of protein O-glycosylation are linked to the synthesis of O-xylosylglycans, O-N-acetylgalactosaminylglycans, O-xylosyl/Nacetylglycans, O-mannosylglycans, and O-fucosylglycans. Clinical features of these disorders are usually limited to one organ or organ system without general symptoms. The following CDG disorders are related to genetic defects in the O-glycosylation pathway and the deficiency of many proteins (enzymes) occur: multiple exostoses, progeroid variant of Ehlers-Danlos syndrome, progeria, familial tumoral calcinosis, Schneckenbecken dysplasia, Walker-Warburg syndrome, spondylocostal dysostosis type 3 , and Peter's Plus syndrome. The diagnostics include a syndromic presentation and organ-specific expression of the disease and laboratory findings. Most of the congenital defects have been found by genetic approaches.

\section{REFERENCES}

Beighton P, Sujansky E, Patzak B, Portele KA (1993) Genetic skeletal dysplasias in the Museum of Pathological Anatomy, Vienna. Am J Med Genet 47: 843-847.

Beltran-Valero de Bernabe D, Currier S, Steinbrecher A, Celli J, van Beusekom E, van der Zwaag B, Kayserili H, Merlini L, Chitayat D, Dobyns WB, Cormand B, Lehesjoki AE, Cruces J, Voit T, Walsh $\mathrm{CA}$, van Bokhoven $\mathrm{H}$, Brunner HG (2002) Mutation in the Omannosyltransferase gene POMT1 give rise to the severe neuronal migration disorder Walker-Warburg syndrome. Am J Hum Genet 71: 1033-1043.

Bennett EP, Hassan H, Clausen H (1996) cDNA cloning and expression of a novel human UDP-N-acetyl- $\alpha$-D-galactosamine. Polypeptide N-acetylgalactosaminyltransferase, GalNAc-t3. J Biol Chem 271: 17006-17012.

Brockhausen I, Schachter H, Stanley P (2009) O-GalNAc Glycans. In Essential of Glycobiology. Varki A, Cummings RD, Esko JD, Freeze HH, Stanley P, Bertozzi CR, Hart GW, Etzler ME, 2nd eds, pp 115-127. Cold Spring Harbor Laboratory Press, Cold Spring Harbor, New York.

Chefetz I, Sprecher E (2009) Familial tumoral calcinosis and the role of O-glycosylation in the maintenance of phosphate homeostasis. Biochim Biophys Acta 1792: 847-852.

Cormand B, Pihko H, Bayes M, Valanne L, Santavuori P, Talim B, Gershoni-Baruch R, Ahmad A, van Bokhoven $\mathrm{H}$, Brunner $\mathrm{HG}$, Voit T, Topaloglu H, Dobyns WB, Lehesjoki AE (2001) Clinical and genetic distinction between Walker-Warburg syndrome and muscle-eye-brain disease. Neurology 56: 1059-1069.

de Jong JG, Wevers RA, Liebrand van Sambeek R (1992) Measuring urinary glycosaminoglycans in the presence of protein: an improved screening procedure for mucopolysaccharidoses based on dimethylmethylene blue. Clin Chem 38: 803-807.

Diesen C, Saarinen A, Pihko H, Rosenlew C, Cormand B, Dobyns WB, Dieguez J, Valanne L, Joensuu T, Lehesjoki A-E (2004) POMGnT1 mutation and phenotypic spectrum in muscle-eye-brain disease. J Med Genet 41: e115.

Duret MH (1899) Tumeurs multiples and singuliers de bourses sereuses. Bull Mem Soc Ant 74: 725-731.

Esko JD, Kimata K, Lindahl U (2009) Proteoglycans and Sulfated Glycosaminoglycans. In Essential of Glycobiology. Varki A, Cummings RD, Esko JD, Freeze HH, Stanley P, Bertozzi CR, Hart GW, Etzler ME, 2nd eds, pp 229-248. Cold Spring Harbor Laboratory Press, Cold Spring Harbor, New York.

Faiyaz-Ul-Haque M, Zaidi SHE, Al-Ali M, Al-Mureikhi MS, Kennedy S, Al-Thani G, Tsui L-C, Teebi AS (2004) A novel missense mutation in the galactosyltransferase-I (B4GALT7) gene in a family exhibiting facioskeletal anomalies and Ehlers-Danlos syndrome resembling the progeroid type. Am J Med Genet A 128: 39-45.

Freeze HH, Haltiwanger RS (2009) Other Classes of ER/Golgi-derived Glycans. In Essential of Glycobiology. Varki A, Cummings RD, Esko JD, Freeze HH, Stanley P, Bertozzi CR, Hart GW, Etzler ME, 2nd eds, pp 163-174. Cold Spring Harbor Laboratory Press, Cold Spring Harbor, New York. 
Freeze HH, Schachter H (2009) Genetic Disorders of Glycosylation. In Essential of Glycobiology. Varki A, Cummings RD, Esko JD, Freeze HH, Stanley P, Bertozzi CR, Hart GW, Etzler ME, 2nd eds, pp 585-600. Cold Spring Harbor Laboratory Press, Cold Spring Harbor, New York.

Furuichi T, Kayserili H, Hiraoka S, Nishimura G, Ohashi H, Alanay Y, Lerena J C, Aslanger AD, Koseki H, Cohn DH, Superti-Furga A, Unger S, Ikegawa S (2009) Identification of loss-of-function mutations of SLC35D1 in patients with Schneckenbecken dysplasia, but not with other severe spondylodysplastic dysplasias group diseases. $J$ Med Genet 46: 562-568.

Giard JM (1898) Sur la calcification hibernale. Compes Rend Seanes Soc Biol So 1013-1015.

Heinritz W, Huffmeier U, Strenge S, Miterski B, Zweier C, Leinun S, Bohring A, Mitulla B, Peters U, Froster UG (2009) New mutations of EXT1 and EXT2 genes in German patients with multiple osteochondromas. Ann Hum Genet 73: 283-291.

Hess D, Keusch JJ, Oberstein SA, Hennekam RC, Hofsteenge J (2008) Peters Plus syndrome is a new congenital disorder of glycosylation and involves defective O-glycosylation of thrombospondin type 1 repeats. I Biol Chem 283: 7354-7360.

Hewitt JE (2009) Abnormal glycosylation of dystroglycan in human genetic disease. Biochim Biophys Acta 1792: 853-861.

Hiraoka S, Furuichi T, Nishimura G, Shibata S, Yanagishita M, Rimoin DL, Superti-Furga A, Nikkels PG, Ogawa M, Katsuyama K, Toyoda H, Kinoshita-Toyoda A, Ishida N, Isono K, Sanai Y, Cohn DH, Koseki H, Ikegawa S (2007) Nucleotide-sugar transporter SLC35D1 is critical to chondroitin sulfate synthesis in cartilage and skeletal development in mouse and human. Nature Med 13: 1363-1367.

Jaeken J, Hennet T, Matthijs G, Freeze HH (2009) CDG nomenclature: time for a change! Biochim Biophys Acta 1792: 825-826.

Jennes I, Entius MM, Van Hul E, Parra A, Sangiorgi L, Wuyts W (2008) Mutation screening of EXT1 and EXT2 by denaturing highperformance liquid chromatography, direct sequencing analysis, fluorescence in situ hybridization, and a new multiplex ligationdependent probe amplification probe set in patients with multiple osteochondromas. J Mol Diagn. 10: 85-92.

Jentoft N (1990) Why are proteins O-glycosylated? Trends Biochem Sci 15: 291-294.

Kano H, Kobayashi K, Herrmann R, Tachikawa M, Manya H, Nishino I, Nonaka I, Straub V, Talim B, Voit T, Topaloglu H, Endo T, Yoshikawa H, Toda T (2002) Deficiency of $\alpha$-dystroglycan in muscleeye-brain disease. Biochem Biophys Res Commun 291: 1283-1286.

Kim D-S, Hayashi YK, Matsumoto H, Ogawa M, Noguchi S, Murakami N, Sakuta R, Mochizuki M, Michele DE, Campbell KP, Nonaka I, Nishino I (2004) POMT1 mutation results in defective glycosylation and loss of laminin-binding activity in alpha-DG. Neurology 62: 1009-1011.

Kresse H, Rosthoj S, Quentin E, Hollmann J, Glossl J, Okada S, Tonnesen $\mathrm{T}$ (1987) Glycosaminoglycan-free small proteoglycan core protein is secreted by fibroblasts from a patient with a syndrome resembling progeroid. Am I Hum Genet 41: 436-453.

Krooth RS, Macklin MT, Hilbish TF (1961) Diaphysial aclasis (multiple exostoses) on Guam. Am J Hum Genet 13: 340-347.

Lawler J, Hynes RO (1986) The structure of human thrombospondin, an adhesive glycoprotein with multiple calcium-binding sites and homologies with several different proteins. I Cell Biol 103: 1635-1648.

Legeai-Mallet L, Munnich A, Maroteaux P, Le Merrer M (1997) Incomplete penetrance and expressivity skewing in hereditary multiple exostoses. Clin Genet 52: 12-16.

Manya H, Chiba A, Yoshida A, Wang X, Chiba Y, Jigami Y, Margolis RU, Endo T (2004) Demonstration of mammalian protein O-mannosyltransferase activity: coexpresion of POMT1 and POMT2 required for enzymatic activity. Proc Natl Acad Sci USA 101: 500-505.

Martinez-Duncker I, Dupre T, Piller V, Piller F, Candelier JJ, Trichet C, Tchernia G, Oriol R, Mollicone R (2005) Genetic complementation reveals a novel human congenital disorder of glycosylation of type II, due to inactivation of the Golgi CMP-sialic acid transporter. Blood 105: 2671-2676.

McClatchie S, Bremner AD (1969) Tumoral calcinosis--an unrecognized disease. Br Med J 1: 153-155.

Michele DE, Barresi R, Kanagawa M, Saito F, Cohn RD, Satz JS, Dollar J, Nishino I, Kelley RI, Somer H, Straub V, Mathews KD, Moore SA, Campbell KP (2002) Post-translational disruption of dystroglycan-ligand interactions in congenital muscular dystrophies. Nature 418: 417-422.

Muraoka M, Kawakita M, Ishida N (2001) Molecular characterization of human UDP-glucuronic acid/UDP-N-acetylgalactosamine transporter, a novel nucleotide sugar transporter with dual substrate specificity. FEBS Lett 495: 87-93.

Okajima T, Fukumoto S, Furukawa K, Urano T, Furukawa K (1999) Molecular basis for the progeroid variant of Ehlers-Danlos syndrome: identification and characterization of two mutations in galactosyltransferase I gene. J Biol Chem 274: 28841-28844.
OMIM. Online Mendelian Inheritance in Man. An Online Catalog of Human Genes and Genetic Disorders. http://www.omim.org/. (updated 25 January 2013).

Phillippe C, Porter DE, Emerton ME, Wells DE, Simpson AH, Monaco AP (1997) Mutation screening of the EXT1 and EXT2 genes in patients with hereditary multiple exostoses. Am J Hum Genet 61: 520-528.

Quentin E, Gladen A, Roden L, Kresse H (1990) A genetic defect in the biosynthesis of dermatan sulfate proteoglycan: galactosyltransferase I deficiency in fibroblasts from a patient with a progeroid syndrome. Proc Natl Acad Sci USA 87: 1342-1346.

Ricketts LM, Dlugosz M, Luther KB, Haltiwanger RS, Majerus EM. (2007) O-fucosylation is required for ADAMTS13 secretion. J Biol Chem 282: 17014-17023.

Sabatelli P, Columbaro M, Mura I, Capanni C, Lattanzi G, Maraldi NM, Beltràn-Valero de Barnabè $\mathrm{D}$, van Bokoven $\mathrm{H}$, Squarzoni $\mathrm{S}$, Merlini L (2003) Extracellular matrix and nuclear abnormalities in skeletal muscle of a patient with Walker-Warburg syndrome caused by POMT1 mutation. Biochim Biophys Acta 20: 57-62.

Santavuori P, Leisti J, Kruus S (1977) Muscle, eye and brain disease: a new syndrome. Neuropediatrie 8 (Suppl): 553-558.

Sparrow DB, Chapman G, Wouters MA, Whittock NV, Ellard S, Fatkin D, Turnpenny PD, Kusumi K, Sillence D, Dunwoodie SL (2006) Mutation of the lunatic fringe gene in humans causes spondylocostal dysostosis with a severe vertebral phenotype. Am J Hum Genet 78: 28-37.

Spiro RG (2002) Protein glycosylation: nature, distribution, enzymatic formation, and disease implications of glycopeptide bonds. Glycobiology 12: 43R-56R.

Ten Hagen KG, Fritz TA, Tabak LA (2003) All in the family: the UDP-GalNAc: polypeptide N-acetylgalactosaminyltransferases. Glycobiology 1: 1R-16R

Topaz O, Nergman R, Mandel U, Maor G, Goldberg R, Richard G, Sprecher E (2005) Absence of intraepidermal glycosyltransferase ppGalNac-T3 expression in familial tumoral calcinosis. Am J Dermatopathol 27: 211-215.

Topaz O, Shuman DL, Bergman R, Indelman M, Ratajczak P, Mizrachi M, Khamaysi Z, Behar D, Petronius D, Friedman V, Zelikovic I, Raimer S, Metzker A, Richard G, Sprecher E (2004) Mutations in GALNT3, encoding a protein involved in O-linked glycosylation, cause familial tumoral calcinosis. Nat Genet 36: 579-581.

Tucker RP (2004) The thrombospondin type 1 repeat superfamily. Int J Biochem Cell Biol 36: 969-974.

Vaith P, Assmann G, Uhlenbruck G (1978) Characterization of the oligosaccharide side chain of apolipoprotein C-III from human plasma very low density lipoproteins. Biochim Biophys Acta 541: 234-240.

van Reeuwijk J, Janssen M, van den Elzen C, Beltran Valero de Bernabe D, Sabatelli P, Merlini L, Boon M, Scheffer H, Brockington M, Muntoni F, Huynen MA, Verrips A, Walsh CA, Barth PG, Brunner HG, van Bokhoven H (2005) POMT2 mutations cause $\alpha$-dystroglycan hypoglycosylation and Walker-Warburg syndrome. $J$ Med Genet 42: 907-912.

Walker AE (1942) Lissencephaly. Arch Neurol Psychiat 48: 13-29.

Wopereis S, Abd Hamid UM, Critchley A, Royle L, Dwek RA, Morava E, Leroy JG, Wilcken B, Lagerwerf AJ, Huijben KM, Lefeber DJ, Rudd PM, Wevers RA (2006) Abnormal glycosylation with hypersialylated O-glycans in patients with Sialuria. Biochim Biophys Acta 1762: 598-607.

Wopereis S, Grunewald S, Huijben KM, Morava E, Mollicone R, van Engelen BG, Lefeber DJ, Wevers RA (2007) Transferrin and apolipoprotein $\mathrm{C}-\mathrm{III}$ isofocusing are complementary in the diagnosis of N- and O-glycan biosynthesis defects. Clin Chem 53: 180-187.

Wopereis S, Grunewald S, Morava E, Penzien JM, Briones P,Garcia Silva MT, Demacker PN, Huijben KM, Wevers RA (2003) Apolipoprotein C-III isofocusing in the diagnosis of genetic defects in O-glycan biosynthesis. Clin Chem 49: 1839-1845.

Wopereis S, Lefeber DJ, Morava E, Wevers RA (2006a) Mechanisms in protein O-glycan Biosynthesis and clinical and molecular aspects of protein O-glycan biosynthesis defects: a review. Clin Chem 52: $574-600$.

Wopereis S, Morava E, Grunewald S, Mills PB, Winchester BG, Clayton P, Coucke P, Huijben KM, Wevers RA (2005) A combined defect in the biosynthesis of $\mathrm{N}$ - and O-glycans in patients with cutis laxa and neurological involvement: the biochemical characteristics. Biochim Biophys Acta 74: 156-164.

Zauner G, Kozak RP, Gardner RA, Fernandes DL, Deelder AM, Wuhrer M (2012) Protein O-glycosylation analysis. Biol Chem 393: 687-708.

Zhang W, Vajsar J, Cao P, Breningstall G, Diesen C, Dobyns W, Herrmann R, Lehesjoki AE, Steinbrecher A, Talim B, Toda T, Topaloglu H, Voit T, Schachter H (2003) Enzymatic diagnostic test for muscle-eye-brain type congenital muscular dystrophy using commercially available reagents. Clin Biochem 36: 339-344. 